\title{
Modeling the interaction between flow and highly flexible aquatic vegetation
}

\author{
J. T. Dijkstra ${ }^{1}$ and R. E. Uittenbogaard ${ }^{2}$ \\ Received 27 February 2010; revised 15 August 2010; accepted 22 October 2010; published 18 December 2010.
}

[1] Aquatic vegetation has an important role in estuaries and rivers by acting as bed stabilizer, filter, food source, and nursing area. However, macrophyte populations worldwide are under high anthropogenic pressure. Protection and restoration efforts will benefit from more insight into the interaction between vegetation, currents, waves, and sediment transport. Most aquatic plants are very flexible, implying that their shape and hence their drag and turbulence production depend on the flow conditions. We have developed a numerical simulation model that describes this dynamic interaction between very flexible vegetation and a time-varying flow, using the sea grass Zostera marina as an example. The model consists of two parts: an existing 1DV $k-\varepsilon$ turbulence model simulating the flow combined with a new model simulating the bending of the plants, based on a force balance that takes account of both vegetation position and buoyancy. We validated this model using observations of positions of flexible plastic strips and of the forces they are subjected to, as well as hydrodynamic measurements. The model predicts important properties like the forces on plants, flow velocity profiles, and turbulence characteristics well. Although the validation data are limited, the results are sufficiently encouraging to consider our model to be of generic value in studying flow processes in fields of flexible vegetation.

Citation: Dijkstra, J. T., and R. E. Uittenbogaard (2010), Modeling the interaction between flow and highly flexible aquatic vegetation, Water Resour. Res., 46, W12547, doi:10.1029/2010WR009246.

\section{Introduction}

[2] Aquatic vegetation is an important part of aquatic ecosystems worldwide. In some areas a number of external human and natural factors are threatening the survival of aquatic plants, particularly sea grasses. When abundant, submerged aquatic vegetation can act as an "ecoengineer," with plants affecting their environment in such a way that they create more favorable living conditions for themselves and for other organisms [Bouma et al., 2005; Bos et al., 2007; Peralta et al., 2008]. In order to asses this ecoengineering ability and to enhance the prospects of success of restoration and protection attempts, more insight is needed into this interaction between vegetation, currents, waves, sediment transport and water quality.

[3] In other areas, the presence of vegetation in rivers and lakes can be problematic as the hydraulic resistance caused by plants might increase water levels. Many empirical [e.g., Kouwen and Unny, 1970, 1973; Järvelä, 2002; Sukhodolov and Sukhodolova, 2006; Wilson et al., 2003] as well as modeling work [e.g., López and García, 2001; Stoesser et al., 2009; Neary, 2003; Nepf, 1999] studied the effect of vegetation on hydraulic resistance. These studies have provided very useful insights, however they mostly focused on rigid or

\footnotetext{
${ }^{1}$ Department of Hydraulic Engineering, Faculty of Civil Engineering and Geosciences, Delft University of Technology, Delft, Netherlands.

${ }^{2}$ Deltares, Delft, Netherlands.

Copyright 2010 by the American Geophysical Union. 0043-1397/10/2010WR009246
}

moderately flexible vegetation, whereas aquatic vegetation systems in estuaries usually consist of very flexible sea grasses.

[4] The interaction of sea grasses with their environment has been subject of numerous studies in the United States [e.g., Fonseca et al., 2002; Koch and Beer, 1996; Abdelrhman, 2003; Ackerman and Okubo, 1993; Worcester, 1995], in the Venice Lagoon (Italy) [Bocci et al., 1997; Sfriso and Marcomini, 1997; Amos et al., 2004] and in other areas [van Katwijk, 2000; Christiansen et al., 1981; Godet et al., 2008; Olesen et al., 2004; Gacia and Duarte, 2001; Tamaki et al., 2002].

[5] Field and laboratory experiments [e.g., Fonseca et al., 1982; Folkard, 2005; Schanz and Asmus, 2003; Ackerman and Okubo, 1993] provide valuable information, but are often expensive, difficult to conduct and have a limited range of applicability. We therefore decided to construct a numerical simulation model that is based on the processes that determine the interaction between flexible vegetation and its environment. With such a generic model, a wide range of characteristics in respect of currents, waves, water depths and vegetation characteristics can be studied.

[6] The first challenge is to model the water motion through a static vegetation field, since the hydrodynamics determine the transport of sediment and nutrients, as well as the forces acting on plants. Vegetation elements are often modeled as rigid objects, but flow patterns in highly flexible vegetation such as sea grass are very different from flow patterns through rigid vegetation. The bending or reconfiguration of plants reduces drag forces considerably [Vogel, 1981; Gaylord and Denny, 1997; Sand-Jensen, 2008; Bouma et al., 2005]. The bending allows for a 


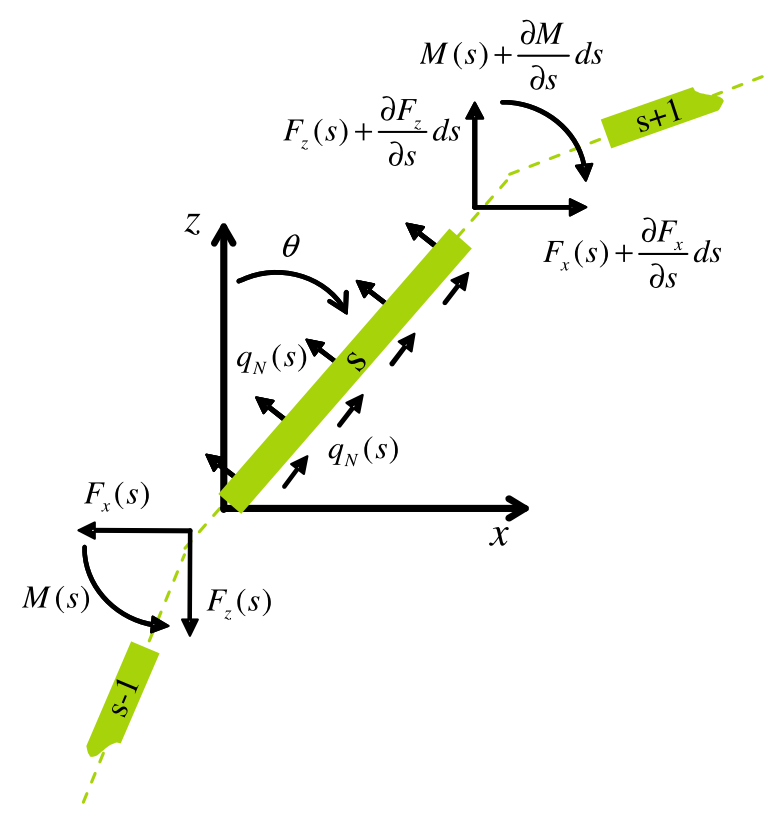

Figure 1. The force balance of one vegetation element $s$ of length $d s$, with adjacent elements $s-1$ and $s+1$.

greater flow over the canopy ("skimming flow") and for a turbulence maximum closer to the bed, whereas the prone leaves can shield the bed from high shear stresses. A second challenge is modeling the reconfiguration of a plant under time-varying flow, i.e., changes in unidirectional flow velocity or waves. Mechanical interactions between plants as well as the intricate structure of branches and leaves of some macrophyte species form further challenges.

[7] In this study, we set out to deal with the first challenge only: demonstrating a modeling approach for unidirectional flow through flexible vegetation. We strive to build on generic principles, while keeping in mind that the model eventually should be applicable to many species of macrophytes in many flow conditions. These latter two challenges require extensive experimental work however. In order not to make matters overly complicated we focus on flexible plastic strips and one plant species: the sea grass Zostera marina. Like most sea grasses, $Z$. marina (eelgrass) has a relatively simple shape: typically five long $(>30 \mathrm{~cm})$, thin $(<0.5 \mathrm{~mm})$ leaves with a rectangular cross section attached to a very short $(<1 \mathrm{~cm})$ stem. This makes eelgrass very flexible, and relatively straightforward to model.

\section{Methods}

[8] The aim is to create a generically applicable tool that is useful in studying flow and flow related exchange processes in fields of different kinds of flexible vegetation, as well as hydrodynamic loads on the vegetation and on the seabed. This means that two interacting models are necessary: one to simulate the hydrodynamics and one to simulate the movement of the plants. The former builds on an earlier model for flow through rigid vegetation by the second author that was presented at a symposium but not published in a journal [Uittenbogaard, 2003], the latter is new. Each model works fully implicitly in time and space for stability, whereas their coupling is formulated semi-implicitly.

\subsection{The Vegetation Model}

[9] The crucial difference with earlier rigid vegetation models is that in this model the movement (i.e., the position, orientation and velocity) of a plant is modeled. The nonstationary nature of flow and plant motion in waves requires dynamic modeling. This has consequences for the numerical scheme because some forces depend linearly others quadratically on the velocity or the acceleration of the leaf. Backhaus and Verduin [2008] coupled a canopy model that simulates motions of plant ensembles to a hydrodynamic model, suitable for the simulation of short waves. Their model is based on field observations of maximum deflection of the sea grass Amphibolis antarctica. For small excitations the plants just follow the orbital motion, only at their maximum deflection plants exert a drag force. This approach works well for surface waves, although it is very speciesspecific. Ikeda et al. [2001] used a 'plant grid' within a large eddy simulation grid to model groups of leaves, assuming the movement of the plant can be described by the equations of motion for a flexible cantilever. Kutija and Hong [1996] modeled the effect of flexible reeds on hydraulic resistance, but without calibration and not taking the interaction of plants with flow into account. With the purpose of predicting the stability of plants in lakes, Schutten and Davy [2000] performed a regression analysis that linked hydraulic drag on flexible plants to flow velocity, biomass and species-specific factors. They did not study the effect of plants on flow. The model of Velasco et al. [2008] provides a reasonable approximation of the vegetation position as well as the velocity and shear profiles in flow through barley, but with the use of a large number of tunable parameters rather than a physical basis. Abdelrhman [2007] successfully developed and tested a two-dimensional model for the coupling of flow and very flexible eelgrass. His model is applicable to stationary flow and very flexible vegetation only, as blade elasticity and is omitted. Otherwise, his approach is partly similar to ours, by modeling a blade as a series of elements.

[10] Because of the need to deal with thin blades that show very large deflections, our method is to follow a Lagrangian approach by setting up a force balance of a plant, consisting of a number of leaf segments (see Figure 1). The coordinate measured along the leaf is $s$, at $s=0$ it is connected to the bed, $s=$ $s_{\max }$ is the tip of the leaf. On every leaf segment $d s$ acts a distributed force $q\left(\mathrm{~N} \mathrm{~m}^{-1}\right)$ as a result of its relative weight and fluid motions relative to the orientation and velocity of the segment. In addition, the force components $F(\mathrm{~N})$ act on the ends of the leaf segment. These are a combination of internal normal and shear stresses, integrated over the leaf cross section.

[11] The following limitations apply: (1) a leaf moves in a single vertical plane only, (2) a leaf cannot fold around itself, (3) a leaf can only bend, not elongate, and (4) biomechanical properties are assumed constant along the leaf. This last limitation is not typical of the model: different properties can be assigned along the leaf, but for simplicity this is not tested in this study.

[12] The force balance for an element with solidity $a\left(\mathrm{~m}^{2}\right)$ reads

$$
\begin{aligned}
& q_{x}+\frac{\partial F_{x}}{\partial s}=\rho_{t} a \frac{\partial^{2} x}{\partial t^{2}} \\
& q_{z}+\frac{\partial F_{z}}{\partial s}=\rho_{t} a \frac{\partial^{2} z}{\partial t^{2}}
\end{aligned}
$$


where $\rho_{t}$ is the total density of the leaf and the surrounding virtual water mass, based on the volumetric density of the vegetation $\rho_{v}$, the water $\rho_{w}$ and a Morison-like virtual mass factor $m_{f}$ [Morison et al., 1950]:

$$
\rho_{t}=\rho_{v}+m_{f} \rho_{w}
$$

The internal force components $F_{x}(s)$ and $F_{z}(s)$, as well as the leaf's positions $x(s)$ and $z(s)$ relative to its root connection are unknowns. A first additional equation couples the internal moment on a cross section to the internal forces:

$$
\frac{\partial M}{\partial s}=\frac{\partial x}{\partial s} F_{z}-\frac{\partial z}{\partial s} F_{x}
$$

The internal moment itself is also unknown, but it is related to the leaf's curvature $\partial \theta / \partial s$ through

$$
E I \frac{\partial \theta}{\partial s}=M
$$

with $E\left(\mathrm{~N} \mathrm{~m}^{-2}\right)$ the elastic modulus of the leaf and $I\left(\mathrm{~m}^{4}\right)$ the moment of inertia, based on width $b$ and thickness $d$.

[13] The essential unknown here is the angle $\theta$ that serves in the leaf's position, assuming no elongation of the leaf:

$$
\begin{aligned}
& \frac{\partial x}{\partial s}=\sin \theta \\
& \frac{\partial z}{\partial s}=\cos \theta
\end{aligned}
$$

Consequently, $x(s)$ and $z(s)$ follow directly from a given angle $\theta(s)$. With equations (1)-(5) the problem is closed and formulated into a single unknown $\theta(s)$.

[14] The following set of boundary conditions applies:

$$
\begin{aligned}
& s=s_{m x}: M=0 ; F_{x}=0 ; F_{z}=0 \\
& s=0: \quad x=0 ; \frac{\partial x}{\partial t}=0 ; \frac{\partial^{2} x}{\partial t^{2}}=0 \\
& s=0: \quad z=0 ; \frac{\partial z}{\partial t}=0 ; \frac{\partial^{2} z}{\partial t^{2}}=0 \\
& s=0: \quad \theta=\theta\{M(0)\}
\end{aligned}
$$

The first condition states that the leaf tip is not loaded; the other conditions fix the position at the bed, but allow for the angle to vary with the total exerted moment $M(0)$, i.e., flexibility in the roots and soil.

[15] The most prominent forces acting on the leaf are those due to pressure differences, but when the relative flow direction is nearly parallel to the leaf, also shear stresses need to be considered:

$$
\begin{aligned}
q_{S} & =\frac{1}{2} \rho_{w} C_{S} b\left|\vec{u}_{w}-\vec{u}_{v}\right| u_{S} \\
q_{N} & =\frac{1}{2} \rho_{w} C_{N} b\left|\vec{u}_{w}-\vec{u}_{v}\right| u_{N}
\end{aligned}
$$

where $q_{S}$ and $q_{N}$ are the force components parallel (i.e., friction) and perpendicular (i.e., lift) to the leaf, respectively. On the right hand side, $\rho_{w}$ is the specific density of water, $C_{S}$ is the friction drag coefficient (actually, $C_{S}=f A_{w}$ with $f$ a friction factor and $A_{w}=2(b+d)$ the wetted area of a leaf) and $C_{N}$ is the coefficient for lift. Further, $\vec{u}_{w}$ and $\vec{u}_{v}$ are the velocity vectors of water and vegetation, respectively, whereas $u_{S}$ and $u_{N}$ are the local velocity components referring to parallel to and normal to the leaf, respectively.

[16] The coefficients $C_{S}$ and $C_{N}$ are complicated because of their dependency on the orientation with respect to the flow and the shape of the cross section. Many observations are available for flat strips perpendicular or almost parallel to the flow, but nothing in between. Drag and lift coefficients along a range of angles could only be found for circular cross sections [e.g., Hoerner, 1965]. We removed this uncertainty by performing experiments with strips of eelgrass-like dimensions at different angles with the flow (section 2.3). It is assumed that the coefficients found for a stiff strip under a certain angle, also apply to a series of leaf sections at local angles $\theta(s)$.

\subsection{The Hydrodynamic Model}

[17] This model is an extension of the 1DV flow model as presented by Uittenbogaard and Klopman [2001] that is suitable for low Reynolds number turbulence by incorporation of the closure of Goldberg and Apsley [1997]. Dispersive stresses [Poggi and Katul, 2008; Nikora and Rowinski, 2008] are not included. Where many models for flow through vegetation have used principles derived from studies on atmospheric boundary layer flow [Finnigan, 2000; Poggi et al., 2004], our model also uses principles of flow through porous media [cf. Breugem et al., 2006], solving for the momentum equation for the pore velocity $u(z)\left(\mathrm{m} \mathrm{s}^{-1}\right)$ :

$$
\begin{aligned}
\rho_{0} \frac{\partial u(z)}{\partial t}+\frac{\partial p}{\partial x}= & \frac{\rho_{w}}{1-A_{p}(z)} \frac{\partial}{\partial z}\left(\left(1-A_{p}(z)\right)\left(\nu+\nu_{T}(z)\right) \frac{\partial u(z)}{\partial z}\right) \\
& -\frac{F(z)}{1-A_{p}(z)}
\end{aligned}
$$

in which $\rho_{w}$ is the fluid density $\left(\mathrm{kg} \mathrm{m}^{-3}\right), \partial p / \partial x$ the horizontal pressure gradient $\left(\mathrm{kg} \mathrm{m}^{-2} \mathrm{~s}^{-2}\right), \nu$ the kinematic viscosity $\left(\mathrm{m}^{2} \mathrm{~s}^{-1}\right), \nu_{T}$ the eddy viscosity $\left(\mathrm{m}^{2} \mathrm{~s}^{-1}\right.$ defined by a turbulence model), and $A_{p}$ (dimensionless) the solidity of the vegetation across a horizontal plane, i.e., the crosssectional area $b(z) \times d(z)\left(\mathrm{m}^{2}\right)$ of a leaf times the number of leaves $(n)$ per $\mathrm{m}^{2}$. Because we consider a horizontal plane, the thickness $d$ depends on the angle of the leaf.

[18] $F(z)$ is the resistance imposed on the flow that follows from the vegetation model according to

$$
F(z)=\frac{1}{2} \rho_{w} C_{D} a(z) u(z)|u(z)|
$$

where $C_{D}$ is the drag coefficient (dimensionless) and $a(z)=$ $d(z) n(z)\left(\mathrm{m}^{-1}\right)$ is the solid area projected on the vertical plane perpendicular to the flow, per unit depth and per unit width. Note that a large number of plants is represented by the position of a single plant. Using this approach, all plants are considered to behave alike, which makes the model applicable to a spatially uniform situation inside a vegetation meadow.

[19] The applied two-equation turbulence model estimates the eddy viscosity through

$$
\nu_{T}=c_{\mu} \frac{k^{2}}{\varepsilon}
$$


with $k$ the turbulent kinetic energy or TKE $\left(\mathrm{m}^{2} \mathrm{~s}^{-2}\right)$, and $\varepsilon$ the dissipation rate $\left(\mathrm{m}^{2} \mathrm{~s}^{-3}\right)$.

[20] The equation for $k$ reads

$$
\frac{\partial k}{\partial t}=\frac{1}{1-A_{p}} \frac{\partial}{\partial z}\left(\left(1-A_{p}\right)\left(\nu+\nu_{T} / \sigma_{k}\right) \frac{\partial k}{\partial z}\right)+T_{k}+P_{k}-\varepsilon
$$

The first term in the RHS represents the vertical diffusion of TKE by its own mixing action, corrected for the available horizontal surface. $T_{k}$ is the additional turbulence generated by the vegetation $\left(\mathrm{Wm}^{-3}\right)$. The amount of power spent by the mean flow $u(z)$ working against the plant drag $F(z)$ depends on the plant Reynolds number $\mathrm{Re}_{\mathrm{p}}$ through the viscous damping function $f$, which is $<1$ for $\mathrm{Re}_{\mathrm{p}}<200$ [Goldberg and Apsley, 1997]:

$$
\begin{aligned}
& T_{k}=f\left(\operatorname{Re}_{p}\right) T ; \quad \operatorname{Re}_{p}=\frac{u d}{\nu} \\
& T(z)=F(z) u(z)
\end{aligned}
$$

The third term, $P_{k}$, represents the standard expression for turbulence production by shear rates:

$$
P_{k}=\nu_{T}\left(\frac{\partial u}{\partial z}\right)^{2}
$$

The last term in equation (11) is the dissipation of TKE by its work against viscous stresses, modeled by the following $\varepsilon$ equation:

$$
\frac{\partial \varepsilon}{\partial t}=\frac{1}{1-A_{p}} \frac{\partial}{\partial z}\left(\left(1-A_{p}\right)\left(\nu+\nu_{T} / \sigma_{\varepsilon}\right) \frac{\partial \varepsilon}{\partial z}\right)+P_{\varepsilon}+c_{2 \varepsilon} \frac{T_{k}}{\tau_{e f f}}-c_{2 \varepsilon} \frac{\varepsilon^{2}}{k}
$$

Here, the first term on the RHS represents vertical diffusion of small-scale eddies, representing $\varepsilon$, by the turbulent eddies. The last term may appear to represent the dissipation of dissipation, but it actually represents the rate at which the energy cascade converts TKE-dissipating eddies into smaller enstrophy-dissipating eddies.

[21] The second term, $P_{\varepsilon}$, is the production of small-scale eddies, scaled to the turbulence production $P_{k}$ by

$$
P_{\varepsilon}=c_{1 \varepsilon}\left(\frac{\varepsilon}{k}\right) P_{k}
$$

The third term of (14) corresponds to the enstrophy production (being dissipation due to vegetation), which depends on the effective time scale $\tau_{\text {eff }}$ and the closure coefficient $c_{2 \varepsilon}$. This time scale is related to the different length scales controlling turbulence in and above vegetation. Internally generated turbulence (IGT) is created at sufficient distance from the bed as well as from the top of the vegetation. Here, the wake turbulence length scale is smaller than the available fluid space. Therefore the time scale of this small-scale IGT equals the intrinsic turbulence time scale:

$$
\tau_{\text {int }}=\frac{k}{\varepsilon}
$$

This time scale is used as effective time scale by Shimizu and Tsujimoto [1994] and López and García [2001].
[22] However, above the vegetation a shear layer exists that creates eddies at larger length scales. Insight from direct numerical simulation by Breugem et al. [2006] shows that these can be advected into the vegetation, thus being squeezed into smaller-scale eddies with a size depending on the available space inside the vegetation. The time scale related to this penetrated flow turbulence (PFT) can be derived by considering a stationary uniform turbulent flow through uniform vegetation, for which, in the absence of diffusion or shear production-dissipation, equals TKE production:

$$
\begin{gathered}
\frac{D k}{D t}=T-\varepsilon \equiv 0 \rightarrow T=\varepsilon \\
\frac{D \varepsilon}{D t}=c_{2 \varepsilon} \frac{T}{\tau}-c_{2 \varepsilon} \frac{\varepsilon^{2}}{k} \equiv 0 \rightarrow k=T \tau
\end{gathered}
$$

We can relate the time scale in equation (18) to a geometrical length scale by comparing the definition of the eddy viscosity in the $k-\varepsilon$ equation (equation (10)) with Prandtl's classical length-scale closure:

$$
v_{\tau}=L \sqrt{k} \equiv c_{\mu} \frac{k^{2}}{\varepsilon} \rightarrow L=c_{\mu} \frac{k^{3 / 2}}{T}
$$

which yields the following expression for the geometryimposed time scale:

$$
\tau_{\text {geom }}=\left(\frac{L_{p}^{2}}{c_{\mu}^{2} T}\right)^{1 / 3}
$$

where $L_{p}$ is the typical length scale between the vegetation defined as

$$
L_{p}(z)=c_{l}\left\{\frac{1-A_{p}(z)}{n(z)}\right\}^{1 / 2}
$$

with $c_{l}$ of order unity.

[23] After calculation of both internal and geometrical time scales over the vertical, the effective time scale for enstrophy production is evaluated by

$$
\tau_{\text {eff }}=\min \left(\tau_{\text {int }}, \tau_{\text {geom }}\right)
$$

The values of the partially interrelated constants $\sigma_{k}, \sigma_{\varepsilon}, c \mu$, $c_{1 \varepsilon}$ and $c_{2 \varepsilon}$ used in equations (11)-(20) are $1,1.3,0.09,1.44$ and 1.92, respectively, equal to those used by López and Garcia [2001] and based on an extensive examination of turbulent shear flows by Launder and Spalding [1974].

\subsection{Setup of Flume Experiments}

[24] The experiment has two objectives: (1) to provide drag and lift coefficients for strips under various angles of attack for use in the flexible vegetation model and (2) to provide a data set of forces and positions of flexible strips with well-known properties for use in validating the model.

[25] All measurements were performed in the racetrack flume of Netherlands Institute for Ecology, Centre for Estuarine and Marine Ecology (NIOO-CEME) in Yerseke, the Netherlands (which has also been used by, e.g., Peralta et al. [2008]; see their article for a picture). The flume is $60 \mathrm{~cm}$ wide and can be filled with fresh or salt water to a depth of $40 \mathrm{~cm}$. A conveyor belt with adjustable rpm creates bulk velocities up to approximately $0.4 \mathrm{~ms}^{-1}$. Collimators 

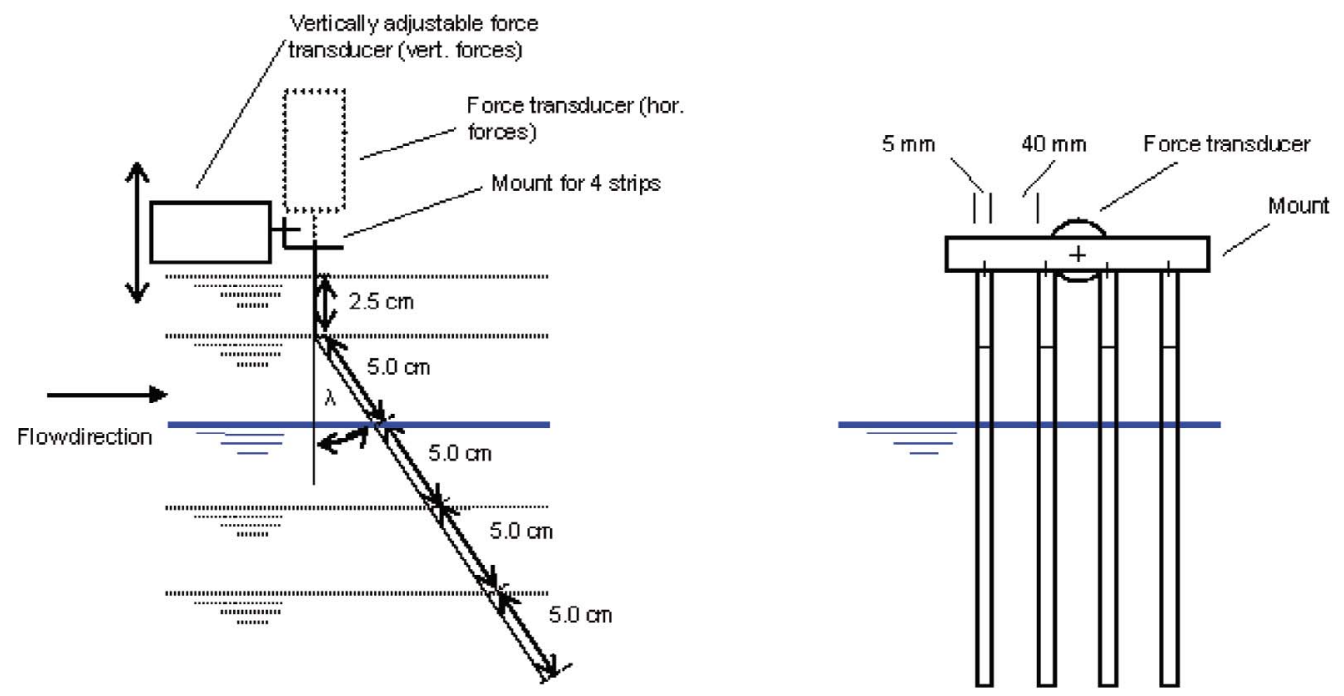

Figure 2. The force transducer mounted with four strips: (left) side view and (right) front view (upstream).

and screens in the bends regulate turbulence and bend effects. For determining the coefficients $C_{N}$ and $C_{S}$, depending on the angle of incidence and on the Reynolds number, the horizontal and vertical forces on inflexible metal strips have been measured with a force transducer. We used strips with a rectangular cross section of $5.0 \mathrm{~mm}$ width and $2.0 \mathrm{~mm}$ thickness.

[26] The angles $(\lambda)$ of the strips ranged from 0 to $90^{\circ}$ relative to vertical, with increments of $10^{\circ}$. For each angle, four strips were mounted onto the force transducer (see Figure 2). The use of four strips proved necessary because at low velocities the force on a single strip was on the lower detection limit of our equipment. A linear relation between the number of strips and the total force proved that strips do not influence each other in this setup (data not shown).

[27] The forces were recorded at bulk velocities of 5.0, $11.4,18.3,25.0,31.8$ and $38.6 \mathrm{~cm} \mathrm{~s}^{-1}$ (see Figure 3 and Table 2). In most cases, measurements were also taken at 2.0 and $8.1 \mathrm{~cm} \mathrm{~s}^{-1}$ for low Reynolds number flows, thereby covering Re numbers from 100 to 1930 . Every recording, hence every raw data file, contains $1 \mathrm{~min}$ of $20 \mathrm{~Hz}$ force measurements, i.e., 1200 values to give a good average. Measurements were done at the upper part of the water column with the largest possible depth $(40 \mathrm{~cm})$ to get the most uniform velocity profile, thus avoiding the logarithmic velocity profile near the bottom.

[28] At the measurement location, $u, v$, and $w$ velocities were recorded using an ADV (Nortek) sampling at $25 \mathrm{~Hz}$ for $5 \mathrm{~s}$ in a grid of 21 points over the vertical and 15 points over the width of the flume; starting at $11 \mathrm{~cm}$ from the bed and $11.6 \mathrm{~cm}$ from the walls. The representative bulk velocity in Figure 3 was acquired by subsequent averaging over time and space. Though the sampling time is actually too short according to Nikora and Goring [1998] and Garcia et al. [2005], we feel that the dense spatial cover combined with earlier reports of rather stationary conditions in this flume (L. Van Duren, personal communication, 2010) gives a sufficiently accurate bulk velocity for our purposes.

\subsection{From Forces to Coefficients}

[29] To derive the coefficients $C_{S}$ and $C_{N}$ as used in the model, the magnitude $(F)$ and direction $(\beta)$ of the total force are calculated from the measured horizontal $\left(F_{H}\right)$ and vertical $\left(F_{V}\right)$ force through

$$
\begin{gathered}
F^{2}=F_{H}^{2}+F_{V}^{2} \\
\beta=\arctan \frac{F_{H}}{F_{V}}
\end{gathered}
$$

Subsequently, the angle $\gamma$ between the force angle $\beta$ and the strip angle $\lambda$ was calculated, enabling the decomposition of $F$ in forces parallel $\left(F_{S}\right)$ and perpendicular $\left(F_{N}\right)$ to the strip:

$$
\begin{gathered}
F_{S}=F \cos \gamma \\
F_{N}=-F \sin \gamma
\end{gathered}
$$

Then, assuming only a horizontal velocity (i.e., $w=0$, $\left.u=u_{H}\right), C_{S}$ and $C_{N}$ are defined as

$$
\begin{aligned}
C_{N} & =\frac{F_{N}}{\frac{1}{2} \rho_{w} A u_{H} u_{N}} \\
C_{S} & =\frac{F_{S}}{\frac{1}{2} \rho_{w} A u_{H} u_{S}}
\end{aligned}
$$

According to the "cross-flow" principle of Hoerner [1965], the following appears valid for circular cross sections:

$$
\begin{aligned}
& C_{N}=C_{D} \cos \lambda \\
& C_{S}=f C_{f} \sin \lambda
\end{aligned}
$$

where $C_{D}$ is a coefficient for the form drag and $C_{f}$ represents skin friction, multiplied by a factor $f$ for the 

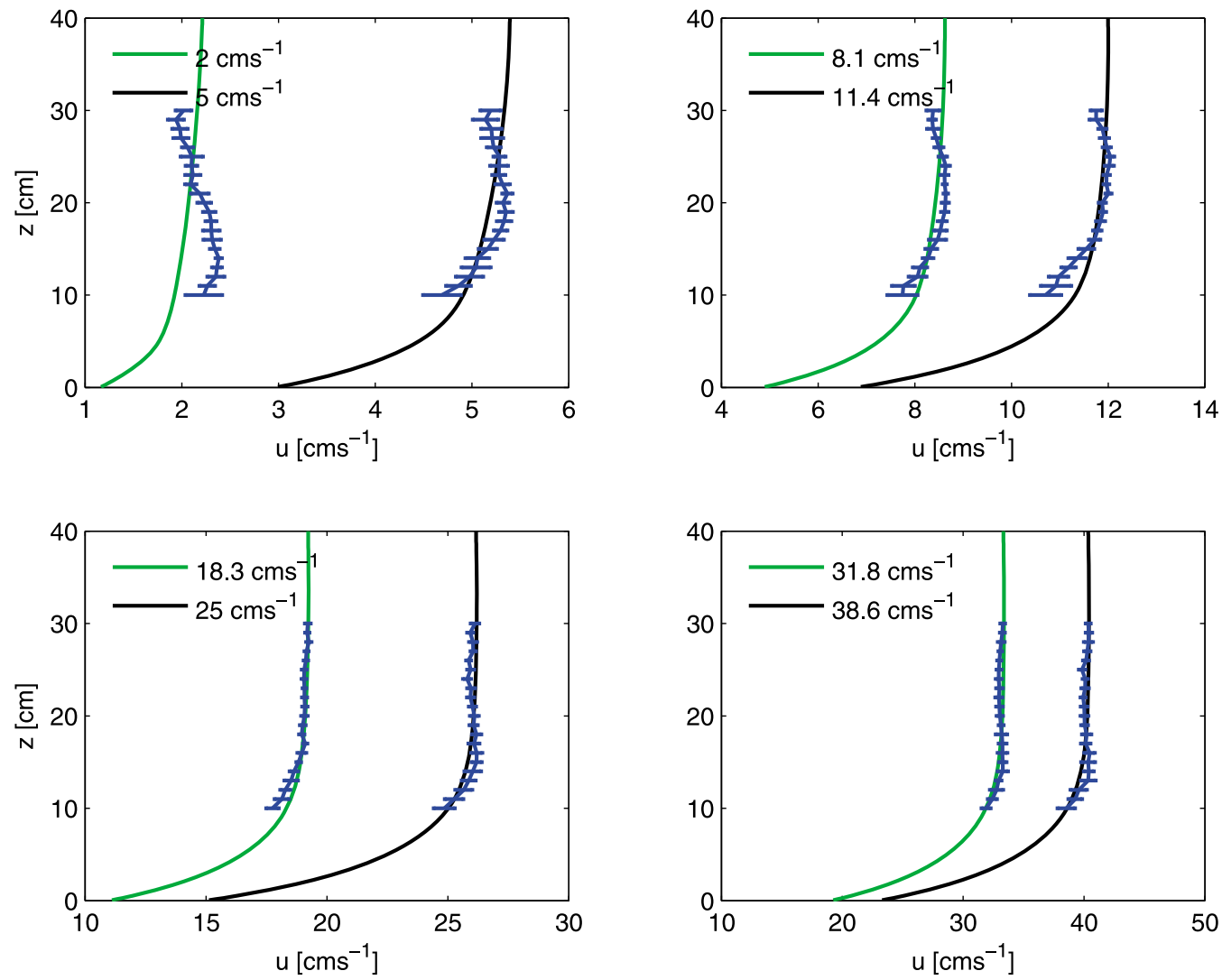

Figure 3. Flow velocity profiles of the empty NIOO flume, averaged over the measurement width. Lines indicate the profiles reproduced by our model, and horizontal error bars indicate the measurements. Note that at low velocities, the velocity profile is not uniform but decreases near the surface.

ratio between the wetted area and the cross section. Here, $f=$ $A_{\text {wet }} / A=2(b+d) / b d=2.8$ holds.

\subsection{Validation Experiments: Flexible Strip Positions}

[30] Three types of plastic strips with different flexural rigidity were used in the same setup and conditions as the metal strips in section 2.3 (Figure 2) to check whether the position of the plant and the forces acting on it are calculated correctly, see Table 1. At various velocities, we measured the force in main flow (i.e., horizontal) direction for a number of strip lengths. For each condition, the positions (Figure 5) have been recorded using two $1 \mathrm{~cm}$ coordinate grids stuck to the flume walls to assure a perpendicular view, marking the position on a transparent sheet. The positions of the transparent strips could not be determined reliably.

[31] As boundary conditions for the model, we used the water depth and depth averaged flow velocity. Measured flow velocity profiles (section 2.3, Figure 3) were used to calibrate the bed wall and sidewall roughness coefficients. The computational grid consists of 100 computational layers over the vertical that zoom in at the bed and the area around the top of the vegetation while following the canopy top. The grid cell height around the vegetation top is $0.01 \mathrm{~mm}$, at the bed level it is $0.1 \mathrm{~mm}$. Each strip consisted of 40 elements. The verification runs in section 3.1 showed that these numerical settings should be more than adequate, which was confirmed by a small sensitivity test.

\subsection{Validation Experiments: Hydrodynamics}

[32] Experimental results from Nepf and Vivoni [2000] were used for validation of the hydrodynamic performance of the model. They applied a $24 \mathrm{~m}$ long and $0.38 \mathrm{~m}$ wide flume, with a $7.4 \mathrm{~m}$ long canopy section consisting of 330 randomly placed $0.16 \mathrm{~m}$ high plants per $\mathrm{m}^{2}$, each made of six $3 \mathrm{~mm}$ wide, $0.25 \mathrm{~mm}$ thick vinyl blades

Table 1. Flexible Strip Properties ${ }^{\mathrm{a}}$

\begin{tabular}{|c|c|c|c|c|c|c|}
\hline Strip & Material & $\mathrm{E}\left(\mathrm{N} \mathrm{m^{-2 }}\right)$ & Thickness (mm) & Width (mm) & $\mathrm{I}\left(\mathrm{m}^{4}\right)$ & Density $\left(\mathrm{kg} \mathrm{m}^{-3}\right)$ \\
\hline Very flexible (FR) & PVC & $1.60 \times 10^{9}$ & 0.178 & 5.0 & $2.30 \times 10^{-15}$ & 975 \\
\hline Tie wrap (TW) & nylon 66 & $1.06 \times 10^{9}$ & 1.009 & 4.8 & $4.11 \times 10^{-13}$ & 1080 \\
\hline Flexible transparent $(\mathrm{FT})$ & copolyester & $1.81 \times 10^{9}$ & 0.540 & 5.0 & $6.56 \times 10^{-14}$ & 1380 \\
\hline Stiff transparent (ST) & copolyester & $1.72 \times 10^{9}$ & 0.981 & 5.0 & $3.93 \times 10^{-13}$ & 1290 \\
\hline
\end{tabular}

${ }^{\mathrm{a}}$ The E modulus was determined with a Perkin Elmer DMA 7e dynamic tester, the thickness was determined with a micrometer, and the width was determined with a digital caliper. 

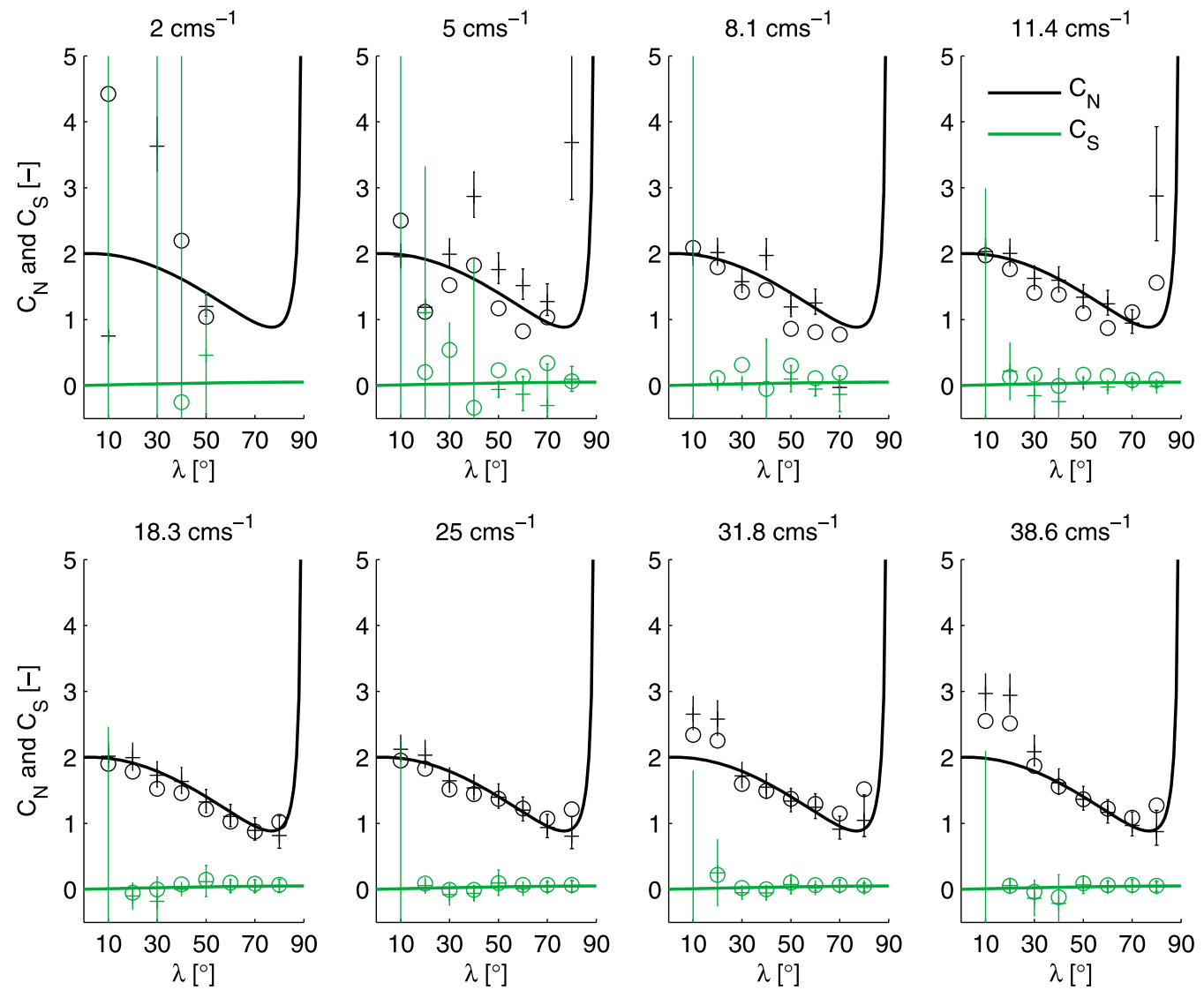

Figure 4. $C_{N}$ and $C_{S}$ for various angles with the vertical plane. The circles are values corrected for tip effects, the crosses are uncorrected values with error bars, and the lines indicate the relation in equation (25).

attached to a $2 \mathrm{~cm}$ high wooden base $(6.4 \mathrm{~mm}$ diameter). The elasticity modulus of the blades is $2.56 \times 10^{9} \mathrm{~N} \mathrm{~m}^{-2}$, derived from the specified flexural rigidity and the moment of inertia. The volumetric density of the material is not mentioned, but estimated at $975 \mathrm{~kg} \mathrm{~m}^{-3}$ because it was slightly buoyant. The best recorded experiment is for a depth of $0.44 \mathrm{~m}$ and a depth averaged velocity of $0.10 \mathrm{~m} \mathrm{~s}^{-1}$.

[33] This water depth and depth averaged velocity were used as boundary conditions in the simulation of their experiments. The roughness coefficients were considered similar to those in the NIOO flume; the numerical settings are equal to those in section 2.5 too.

\section{Results}

\subsection{Verification Runs}

[34] As a first simple check of the model, we compared the bending of a relatively stiff strip under a uniformly distributed load in our model with the theoretical solutions for cantilevers [see, e.g., Gere and Timoshenko, 1999]. The result were essentially the same.

[35] Further, we verified the behavior of the model for a number of simple cases with "standard" conditions (water depth $h=0.5 \mathrm{~m}$, depth averaged flow velocity $U=0.2 \mathrm{~m} \mathrm{~s}^{-1}$, leaf length $l=0.25 \mathrm{~m}$, leaf width $b=5 \mathrm{~mm}$, thickness $d=$ $0.3 \mathrm{~mm}, E=2 \cdot 10^{9} \mathrm{~N} \mathrm{~m}^{-2}, \rho_{v}=920 \mathrm{~kg} \mathrm{~m}^{-3}, \rho_{w}=1000 \mathrm{~kg} \mathrm{~m}^{-3}$, $n=100$ stems $\mathrm{m}^{-2}, 40$ elements per stem) representative of field and laboratory conditions. Without showing data or going into too much detail, we found that (1) time steps of $d t=0.01$ to $d t=1 \mathrm{~s}$ yield similar solutions; (2) 50 to 100 layers over the vertical yield the same solutions; the result of 20 layers is very similar but slightly coarser; and (3) 20 or more elements are necessary to represent the plant position well.

[36] In addition, we varied some properties of the plants, leading to the following observations.

[37] 1. An increased tissue density (range: $1-2000 \mathrm{~kg} \mathrm{~m}^{-3}$ ) leads to increased bending, but the effect on flow properties is limited as the chosen number of plants is small.

[38] 2. An increase in number of plants (range: 1$10000 \mathrm{~m}^{-2}$ ) leads to a more upright position, larger turbulence production and a distinctly different flow profile.

[39] 3. Short plants $(0.05 \mathrm{~m})$ remain almost upright, experience more drag and have more effect on flow than plants of intermediate lengths $(0.25$ and $0.50 \mathrm{~m})$ that assume a more streamlined position. Longer plants $(1-2 \mathrm{~m})$ bend further, but do create more resistance due to skin friction.

[40] 4. The stiffer the plant $\left(E=1 \times 10^{2}\right.$ to $\left.10^{14} \mathrm{~N} \mathrm{~m}^{-2}\right)$, the more upright it stays and the more drag it creates. Due to rapid movement, stable simulations on very flexible plants require a smaller time step to remain stable.

[41] 5. At higher flow velocities $\left(0-2 \mathrm{~m} \mathrm{~s}^{-1}\right)$ plants bend more.

[42] 6. For increasing water depths $(0.05-5 \mathrm{~m})$, the bending of the plants as well as their effect on flow decrease markedly as more flow passes over the plants. 

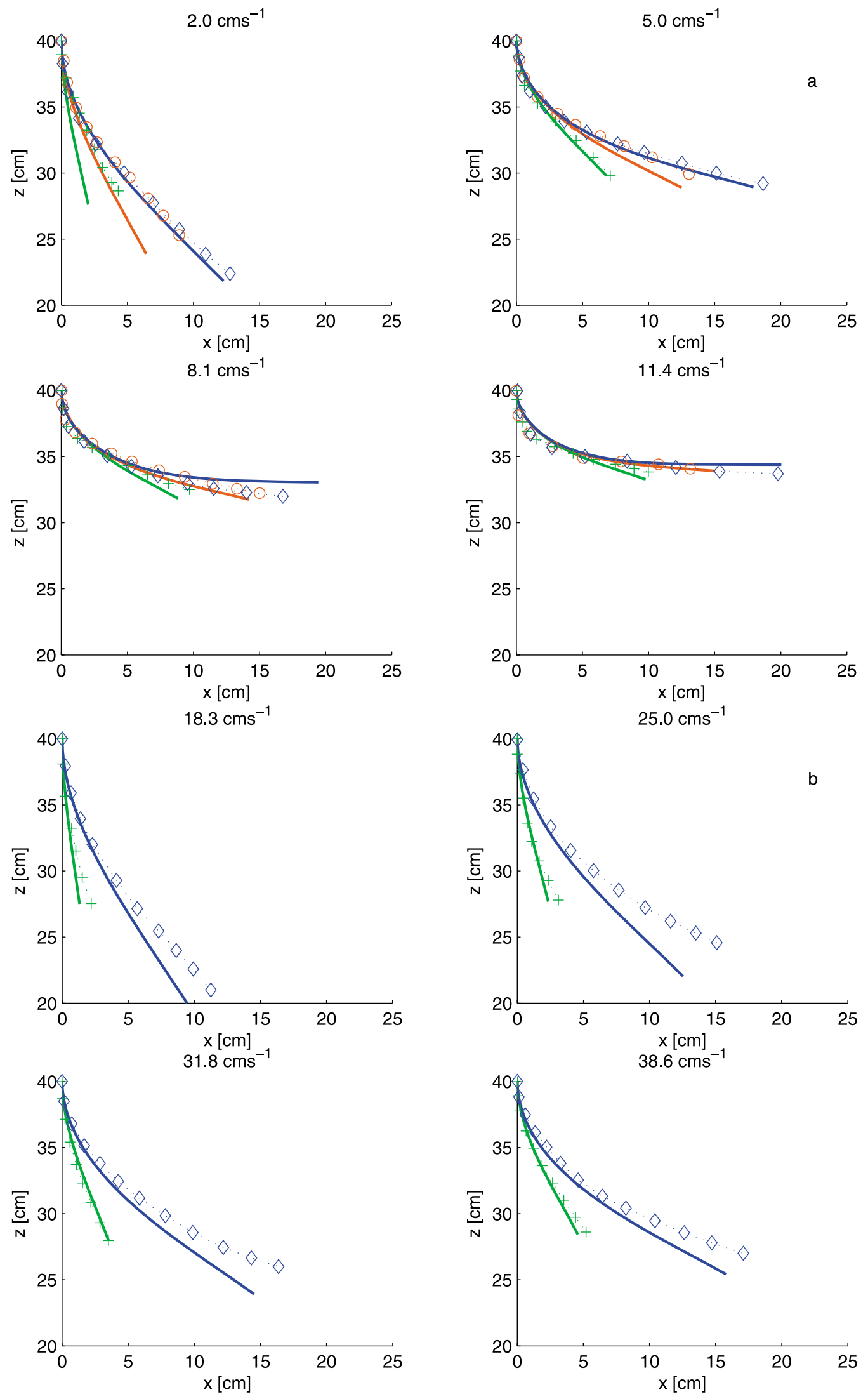

Figure 5. Positions of the (a) very flexible strips (FR) and (b) tie wraps (TW) at four velocities and different lengths. Crosses, circles, and diamonds indicate measurements for strips of 12.7, 17.7, and $22.7 \mathrm{~cm}$, respectively. The solid lines are the model predictions. 
Table 2. Forces and Relative Errors

\begin{tabular}{|c|c|c|c|c|c|c|c|c|c|c|}
\hline \multirow[b]{2}{*}{$\begin{array}{c}\mathrm{U} \\
\left(\mathrm{cm} \mathrm{s}^{-1}\right)\end{array}$} & \multirow[b]{2}{*}{$\begin{array}{c}\mathrm{L} \\
(\mathrm{m})\end{array}$} & \multicolumn{3}{|c|}{$\mathrm{FR}$} & \multicolumn{3}{|c|}{ TW } & \multicolumn{3}{|c|}{ ST } \\
\hline & & $\begin{array}{c}F_{\text {model }} \\
\left(10^{-2} \mathrm{~N}\right)\end{array}$ & $\begin{array}{c}\mathrm{F}_{\exp } \\
\left(10^{-2} \mathrm{~N}\right)\end{array}$ & $\begin{array}{c}\text { Error } \\
(\%)\end{array}$ & $\begin{array}{c}F_{\text {model }} \\
\left(10^{-2} \mathrm{~N}\right)\end{array}$ & $\begin{array}{c}\mathrm{F}_{\exp } \\
\left(10^{-2} \mathrm{~N}\right)\end{array}$ & $\begin{array}{c}\text { Error } \\
(\%)\end{array}$ & $\begin{array}{c}\mathrm{F}_{\text {model }} \\
\left(10^{-2} \mathrm{~N}\right)\end{array}$ & $\begin{array}{c}F_{\text {exp }} \\
\left(10^{-2} \mathrm{~N}\right)\end{array}$ & $\begin{array}{c}\text { Error } \\
(\%)\end{array}$ \\
\hline 2.0 & 0.127 & 0.03 & 0.05 & -33.9 & 0.03 & & & & & \\
\hline 2.0 & 0.177 & 0.03 & $0.03^{\mathrm{a}}$ & 28.6 & & & & & & \\
\hline 2.0 & 0.227 & 0.03 & 0.05 & -30.0 & 0.05 & 0.06 & -19.4 & & & \\
\hline 5.0 & 0.127 & 0.11 & 0.12 & -2.9 & $0.18^{\mathrm{b}}$ & 0.15 & 21.6 & 0.19 & $0.11^{\mathrm{b}}$ & 70.6 \\
\hline 5.0 & 0.177 & 0.10 & 0.10 & 0.9 & & & & 0.26 & 0.26 & -2.2 \\
\hline 5.0 & 0.227 & 0.10 & 0.10 & -7.0 & 0.31 & 0.34 & -7.6 & 0.33 & 0.34 & -2.7 \\
\hline 8.1 & 0.127 & 0.19 & 0.22 & -13.5 & 0.46 & 0.00 & & & & \\
\hline 8.1 & 0.177 & 0.18 & 0.20 & -9.4 & & & & & & \\
\hline 8.1 & 0.227 & 0.18 & 0.23 & -20.9 & 0.80 & 0.79 & 1.6 & & & \\
\hline 11.4 & 0.127 & 0.29 & 0.28 & 4.0 & $0.89^{\mathrm{b}}$ & 0.76 & 17.8 & 0.93 & $0.78^{\mathrm{b}}$ & 19.7 \\
\hline 11.4 & 0.177 & 0.28 & 0.29 & -0.2 & & & & 1.28 & 1.27 & 0.9 \\
\hline 11.4 & 0.227 & 0.29 & 0.33 & -12.3 & 1.48 & 1.36 & 8.9 & 1.60 & $1.65^{\mathrm{c}}$ & -3.1 \\
\hline 18.3 & 0.127 & 0.54 & 0.48 & 12.6 & 2.27 & 1.74 & 30.5 & 2.38 & $2.05^{\mathrm{b}}$ & 15.9 \\
\hline 18.3 & 0.177 & 0.56 & 0.49 & 12.5 & & & & 3.18 & $3.22^{\mathrm{c}}$ & -1.5 \\
\hline 18.3 & 0.227 & 0.58 & 0.53 & 9.1 & 3.08 & 2.89 & 6.7 & 3.62 & $4.18^{\mathrm{c}}$ & -13.6 \\
\hline 25.0 & 0.127 & 0.82 & 0.72 & 14.4 & 4.06 & 3.29 & 23.3 & 4.34 & $4.26^{\mathrm{b}}$ & 1.9 \\
\hline 25.0 & 0.177 & 0.86 & 0.76 & 12.9 & & & & 5.38 & $6.32^{\mathrm{c}}$ & -15.0 \\
\hline 25.0 & 0.227 & 0.90 & 0.80 & 11.8 & 4.47 & 3.57 & 25.4 & 5.50 & $6.51^{\mathrm{c}}$ & -15.4 \\
\hline 31.8 & 0.127 & 1.16 & 0.97 & 19.9 & 6.17 & 4.81 & 28.3 & 6.80 & 6.84 & -0.6 \\
\hline 31.8 & 0.177 & 1.22 & 1.04 & 17.3 & & & & 7.63 & $9.00^{\mathrm{c}}$ & -15.3 \\
\hline 31.8 & 0.227 & 1.27 & 1.06 & 19.3 & 5.86 & 4.22 & 38.8 & 7.29 & $7.33^{\mathrm{c}}$ & -0.5 \\
\hline 38.6 & 0.127 & 1.53 & 0.98 & 55.5 & 8.25 & 6.48 & 27.2 & 9.42 & 10.24 & -8.0 \\
\hline 38.6 & 0.177 & 1.61 & 1.07 & 49.6 & & & & 9.68 & $10.38^{\mathrm{c}}$ & -6.7 \\
\hline 38.6 & 0.227 & 1.67 & 1.09 & 53.6 & 7.28 & 4.93 & 47.5 & 9.02 & 8.18 & 10.2 \\
\hline
\end{tabular}

${ }^{\mathrm{a}}$ Measurement error.

${ }^{\mathrm{b}}$ These values are too low, probably as a result of a lower flow velocity in the upper part of the water column that could not be measured. These values are considered too low because the maximum increase in force with respect to the other strip lengths exceeds with a linear relation.

${ }^{\mathrm{c}}$ For these measurements, the strips vibrate.

\subsection{Forces and Values of Coefficients}

[43] In Figure 4 the values for $C_{S}$ and $C_{N}$, determined from the experiments through equation (23), are plotted against the angle $\lambda$. The coefficients seem to be fairly equal at all flow velocities, although at lower velocities measurements were difficult and less accurate. At higher velocities, the strips started to vibrate at low angles relative to vertical, resulting in a higher drag coefficient. Therefore, the values measured at the intermediate $U=18.3 \mathrm{~cm} \mathrm{~s}^{-1}$ are used.

[44] For a fit, equation (27) would be an obvious starting point. However, in the case of $C_{N}$ this is not possible; especially values at high angles (i.e., a "flatter" orientation) are much higher. To account for these higher values, the following fit was made:

$$
\begin{aligned}
& C_{N}=\min (2 \cos \lambda+0.1 \tan \lambda, 2 \pi) \\
& C_{S}=0.018 f \sin \lambda
\end{aligned}
$$

In the model, $C_{N}$ is limited to $2 \pi$ for stability reasons, a value often used for plates at small angles of attack, see Hoerner [1965].

\subsection{Validation With Flexible Strips}

[45] Figure 5 shows the positions of very flexible and rather stiff plastic strips at different flow velocities and different lengths, whereas Table 2 lists the forces. Like the metal strips, the plastic strips started to vibrate at high flow velocities, possibly resulting in a different drag coefficient, which has not been included in the model. Also, measurements at 2.0 and $5.0 \mathrm{~cm} \mathrm{~s}^{-1}$ are less accurate (see section 2.3). Possible errors in equipment, experimental setup and the measurement of strip properties give an accuracy of $11 \%$ for the forces and $1 \mathrm{~cm}$ for the positions.

\section{Discussion}

[46] The general behavior of the model as discussed in section 3.1 matched our expectations as well as observations recorded in literature. Our simulations clearly show that longer plants do not necessarily create more drag, similar to our own observations and those of Vogel [1981] and Bouma et al. [2005].

[47] Our model appeared to be very sensitive to the number of stem elements. At the same time, this number affects the computation time negatively, up to a power of four. To alleviate this problem we incorporated a logarithmic distribution of element increments ( $d s$ in equations (1)-(5)), concentrating many small elements near the fixation point (where most bending occurs, hence resolution is required) and longer increments toward the free and straight tip.

\subsection{Performance of the Model: Forces and Positions}

[48] In many cases, especially at intermediate flow velocities, the predicted forces are fairly close to the measured values (Table 2). In some cases model predictions deviate more than the expected measurement precision, but they do show an internal consistency similar to that of the measurements. Therefore, the results are considered to be useful.

[49] At the lowest flow velocities, the performance of the model is difficult to determine, since the forces are close to the lower detection limit of our equipment and the velocity profiles are not uniform along the strip (Figure 3). 

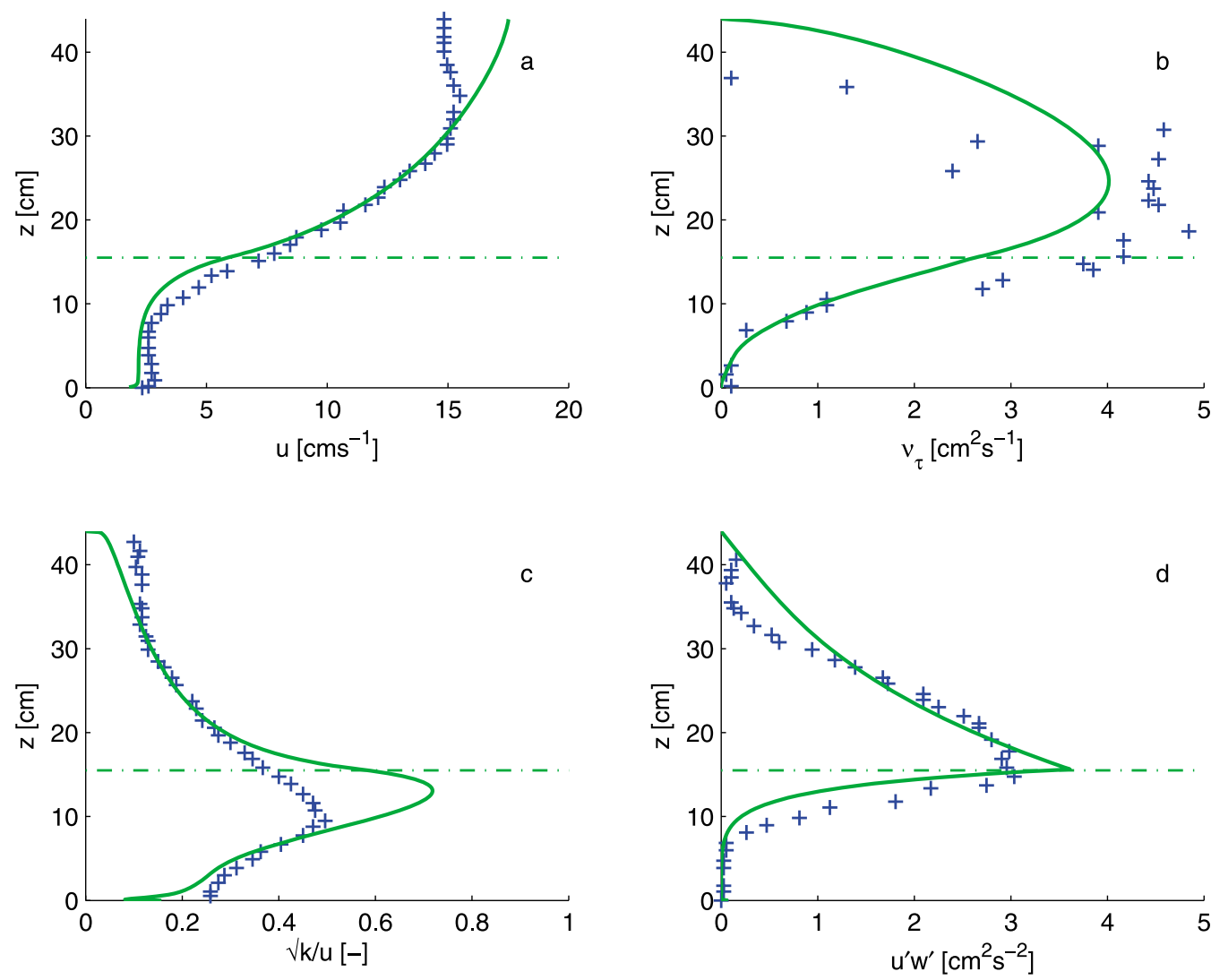

Figure 6. Vertical profiles of hydrodynamic properties as predicted by the model (solid line), measured by Nepf and Vivoni [2000] (crosses): (a) horizontal velocity, (b) eddy viscosity, (c) turbulence intensity, and (d) Reynolds stress The dash-dotted line indicates the height of the canopy.

Nevertheless, the results are not far off, though generally underpredicted. This difference might be explained by the model's drag and lift coefficients' independence of the Reynolds number, whereas at these low Re numbers the measurements on stiff strips indicated higher values.

[50] Apart from some individual anomalies, the structural differences in both forces and positions between the model and the experiments can be explained by a possible dissimilarity of the velocity profile: in the model, the simulated velocity profile is uniform over the upper part of the water column, whereas in the experiment appears to be slightly lower close to the water level. That close to the fixed end of the strips, this lower velocity hardly affects bending, but it does reduce the force quadratically. On the other hand, if the velocity at the tip is slightly higher, the position will be strongly affected due to the larger leverage, but due to the more streamlined orientation of the strips the resulting increase in force is minimal.

[51] The structural underprediction of the forces and positions for the stiff transparent strips (ST, Table 2, footnote c) might be attributed to the drag increasing flutter, a phenomenon not incorporated in the model. The measurements on the stiff metal strips clearly show an increase (about $25 \%$ ) in drag if flutter occurs.

\subsection{Performance of the Model: Hydrodynamics}

[52] Figure 6 shows a comparison of the experiment and model simulations. The agreement with the measurements of Nepf and Vivoni [2000] is fairly good, especially in the vegetated part of the water column. The discrepancies near the water surface are probably the result of sidewall friction in their rather narrow flume causing secondary flows. Another small, but coherent deviation from the measurements is the slight underestimation of the velocity especially just below the top of the canopy, combined with an overestimation of the turbulence intensity in this area. This indicates that we either underestimate the penetration of momentum from the free flow into the canopy, which would lead to a higher velocity inside the canopy, or that we slightly underestimate the canopy height itself. The latter corresponds to our finding that the plants in our model remain very upright, which is probably due to the very high, but not directly measured, modulus of elasticity.

[53] To study the effect of different canopy heights on flow properties, we compared these validation results with those of simulations based on the same settings, but with completely rigid $\left(E=2 \times 10^{12} \mathrm{~N} \mathrm{~m}^{-2}\right)$ and naturally flexible $\left(E=2 \times 10^{7} \mathrm{~N} \mathrm{~m}^{-2}\right)$ vegetation. Figure 7 shows that the experimental results of Nepf and Vivoni [2000] and rigid vegetation are very similar, whereas the more flexible vegetation leads to a lower canopy with higher flow velocities inside. For a comparison with more traditional methods of incorporating the effect of vegetation in a hydrodynamic model, we also made a simulation with a smooth bed without vegetation and one in which the vegetation is mimicked by a bed roughness coefficient (in this case a 

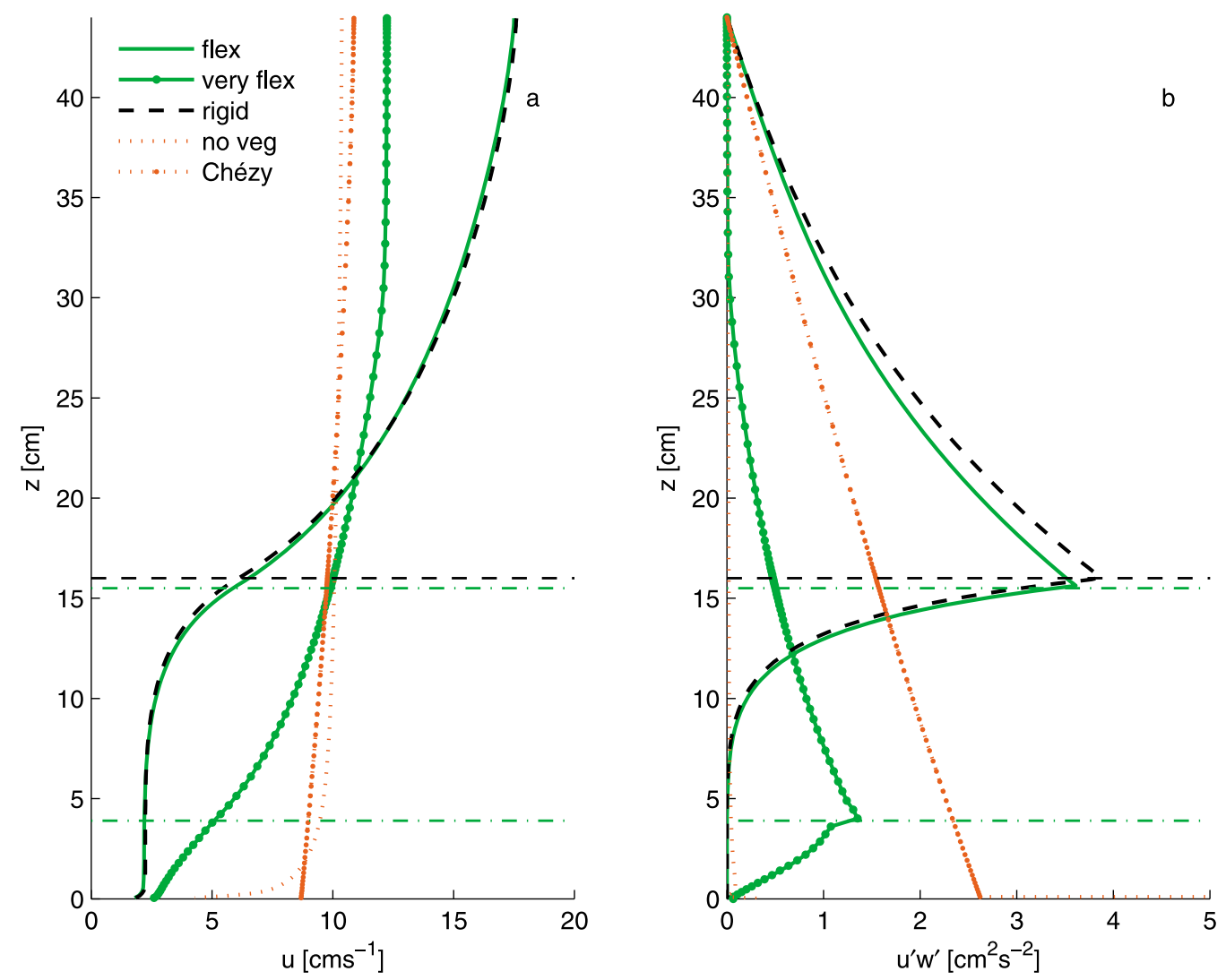

Figure 7. Comparison of flow properties for five different scenarios, all at a depth-averaged velocity of $10 \mathrm{~cm} \mathrm{~s}^{-1}$ with the same vegetation as used in Figure 6, with more flexible vegetation, with rigid vegetation of the same size, without vegetation, and without vegetation but with a representative bed roughness (Chézy coefficient). (a) Horizontal velocity. (b) Reynolds stress. Horizontal lines indicate canopy height.

Chézy coefficient of $8.78 \mathrm{~m}^{1 / 2} \mathrm{~s}^{-1}$, based on flume dimensions and water level gradient). Figure 7 clearly shows that the flow profiles are very different at the same depthaveraged velocity. Especially the transfer of momentum to the bed, paramount in erosion studies, is greatly overestimated when using the traditional methods of a higher bed roughness factor: the bed shear stress would amount $0.26 \mathrm{~N} \mathrm{~m}^{-2}$ in that case, whereas our model indicates values of $0.0024 \mathrm{~N} \mathrm{~m}^{-2}$ in case of flexible vegetation, $0.0025 \mathrm{~N} \mathrm{~m}^{-2}$ for rigid vegetation. As a comparison, the computed values in case of very flexible vegetation are $0.0050 \mathrm{~N} \mathrm{~m}^{-2}$ and $0.013 \mathrm{~N} \mathrm{~m}^{-2}$ for a bare bed.

\subsection{Comparison to Other Work}

[54] An interesting test of the model's general applicability would be a comparison to other experiments on (artificial) sea grass, like those of Folkard [2005], Maltese et al. [2007], Abdelrhman [2003, 2007], and Gambi et al. [1990]. However, either their recording of vegetation properties, the complicated shape of their vegetation meadow or the single dimension of our model hampers a good comparison. This indicates the two major drawbacks of our model: it does not deal with spatial variability or complicated plant forms and it requires the input of vegetation properties that are not usually measured such as the modulus of elasticity. At the same time, the reliance on vegetation properties is one of the main advantages of our model: when these physical properties are known, there is no need for estimating "drag" coefficients like for example in the model of Velasco et al. [2008].

\subsection{Interaction Between Plant Properties and Flow}

[55] To show the effects of changes in plant properties on flow properties and vice versa, we made a series of simulations in similar conditions as discussed in section 4.2, though with some small changes: Figure 8 shows what happens if from the standard set of parameters (depth averaged velocity, depth, plant elasticity or spatial density), one is changed. The standard settings are $U=20 \mathrm{~cm} \mathrm{~s}^{-1}, h=$ $50 \mathrm{~cm}$, flume width $38 \mathrm{~cm}$, bed roughness $C=80 \mathrm{~m}^{1 / 2} \mathrm{~s}^{-1}$ and 1000 plants per $\mathrm{m}^{2}$ with $l=0.25 \mathrm{~m}, b=3 \mathrm{~mm}, d=$ $0.35 \mathrm{~mm}, \rho_{v}=920 \mathrm{~kg} \mathrm{~m}^{-3}$ and $E=20 \mathrm{~N} \mathrm{~m}^{-2}$. These simulations should be seen as a first exploration, since many combinations are possible in nature. We feel that in some circumstances the one parameter is decisive, whereas in other conditions the effect of this single parameter may be rendered insignificant by others; for example, in very dense fields the properties of individual plants may not matter anymore. However, a thorough study into all mutual influences is beyond the scope of this article.

[56] An increasing flow velocity means that the plants will bend more and the bed shear stress is higher. For 

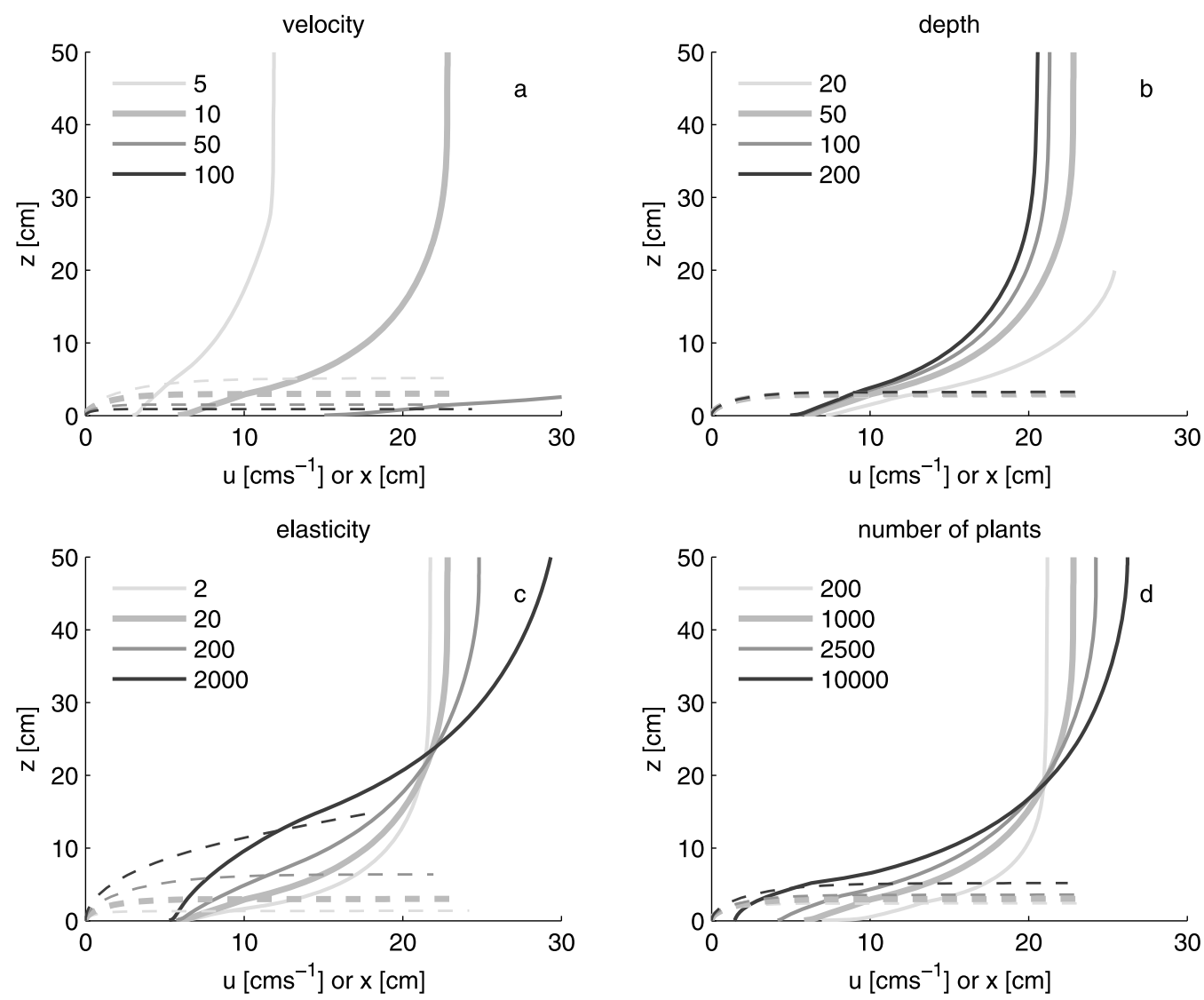

Figure 8. Flow velocity profiles (solid lines) and plant positions (dashed lines) in a flume for (a) various depth-averaged velocities $\left(\mathrm{cm} \mathrm{s}^{-1}\right)$, (b) various flow depths $(\mathrm{cm})$, (c) various elasticities (MPa), and (d) different plant densities $\left(\mathrm{m}^{-2}\right)$. All other properties remained constant, as indicated by the slightly thicker line of the second value in each graph: length $25 \mathrm{~cm}$, width $3 \mathrm{~mm}$, and thickness $0.35 \mathrm{~mm}$.

increasing depths there is not much difference because the ratio of free flow to canopy flow is large in most cases, except for the shallowest condition where more water is forced through the canopy. Changes in elasticity seem to have the strongest effect on flow and plant position: The stiffer the plants, the higher they reach into the water column and the more they divert flow from the canopy toward higher regions. The flow velocity near the bed however is very similar in all cases. A larger plant thickness would do the same, as both thickness and elasticity contribute to flexural rigidity. A denser canopy does lower the velocity close to the bed considerably, but only the highest density has a considerable effect on the plant position.

\subsection{Applicability and Further Work}

[57] With the model in its current form, one can look in detail at processes in and above a vegetation field, and derive properties that govern the exchange of substances and the survival of plants. This model could also be used as a predictor of bed roughness coefficients for areas with flexible vegetation, such as estuaries and rivers, thus expanding the possibilities of other hydrodynamic models that do not account for vegetation explicitly.

[58] The inclusion of spatial variability and the possibility to study plants with nonuniform properties along their length are subject of current research. A similar extension into three dimensions has already been successfully made for an earlier rigid version of this model [Temmerman et al. 2005]. Other improvements to the model would be including more natural meadow-related issues like the mechanical interaction between blades, the effect of plants sheltering in each other's wakes [Raupach, 1992; Nepf, 1999] and effects of other organisms, e.g., epiphytes on blades. In our opinion, each of these topics would justify separate studies that require a substantial experimental basis. On a different track, assessing the model's performance in wave conditions is also worthwhile.

\section{Conclusions}

[59] In conclusion, our model for flow trough very flexible vegetation performs well. Its achievement in determining the position and forces of strips of three different materials, at various lengths and flow velocities, indicates that the model and the drag/lift coefficients are generally applicable. As very flexible plants can assume a position almost parallel to the flow direction, it is not sufficient to take only the drag perpendicular to a leaf into account. The predicted hydrodynamic properties also compare quite well to measurements and are based on measurable physical input parameters rather than estimated tuning coefficients. The incorporation of flexible vegetation gives more realistic 
results than the use of rigid vegetation or the use of an adjusted bed roughness coefficient. The model is sensitive to plant parameters though; particularly the stem thickness and the elasticity. The latter can be difficult to measure. Another limitation is the fact that the model does not deal with spatial variability, complicated plant shapes or mechanical interactions between plants. The flow velocity has a much stronger effect on the plant position than the depth and the structural rigidity is more influential than the number of plants per area.

[60] Overall, the performance of the model is good. Validation data are limited however and the hydrodynamic performance is validated only against measurements in rather common flow conditions. The model should also be tested against measurements of more extreme situations: higher and lower flow velocities, more flexible vegetation, different relative flow depths and different vegetation configurations.

[61] Because we realistically predict plant positions, forces on plants, hydrodynamic properties and bed shear stress reduction, we consider our model a useful improvement. The basis of physically measurable input parameters provides us with a very useful and generic tool in studying flow and exchange processes in fields of flexible vegetation.

[62] Acknowledgments. We thank NIOO-CEME for the use of their experimental facilities, Luca van Duren for help on flume data, Ben Norder of DelftChemTech for determining the properties of the artificial vegetation, and three anonymous reviewers for their valuable comments. The first author is funded by the NWO LOICZ-program under grant 014.27.014.

\section{References}

Abdelrhman, M. A. (2003), Effect of eelgrass Zostera marina canopies on flow and transport, Mar. Ecol. Prog. Ser., 248, 67-83, doi:10.3354/ meps 248067.

Abdelrhman, M. A. (2007), Modeling coupling between eelgrass Zostera marina and water flow, Mar. Ecol. Prog. Ser., 338, 81-96, doi:10.3354/ meps338081.

Ackerman, J. D., and A. Okubo (1993), Reduced mixing in a marine macrophyte canopy, Funct. Ecol., 7, 305-309, doi:10.2307/2390209.

Amos, C. L., et al. (2004), The stability of tidal flats in Venice LagoonThe results of in-situ measurements using two benthic, annular flumes, J. Mar. Syst., 51(1-4), 211-241, doi:10.1016/j.jmarsys.2004.05.013.

Backhaus, J. O., and J. J. Verduin (2008), Simulating the interaction of seagrasses with their ambient flow, Estuarine Coastal Shelf Sci., 80(4), 563-572, doi:10.1016/j.ecss.2008.09.013.

Bocci, M., G. Goffaro, and G. Bendoricchio (1997), Modelling biomass and nutrient dynamics in eelgrass (Zostera marina L.): Applications to the Lagoon of Venice (Italy) and Oresund (Denmark), Ecol. Modell., 102(1), 67-80, doi:10.1016/S0304-3800(97)00095-1.

Bos, A. R., T. J. Bouma, G. L. J. de Kort, and M. M. van Katwijk (2007), Ecosystem engineering by annual intertidal seagrass beds: Sediment accretion and modification, Estuarine Coastal Shelf Sci., 74(1-2), 344-348, doi:10.1016/j.ecss.2007.04.006.

Bouma, T. J., M. B. de Vries, E. Low, G. Peralta, I. C. Tanczos, J. van de Koppel, and P. M. J. Herman (2005), Trade-offs related to ecosystemengineering: A case study on stiffness of emerging macrophytes, Ecology, 86(8), 2187-2199, doi:10.1890/04-1588.

Breugem, W. P., B. J. Boersma, and R. E. Uittenbogaard (2006), The influence of wall permeability on turbulent channel flow, J. Fluid Mech., 562, 35-72, doi:10.1017/S0022112006000887.

Christiansen, C., H. Christoffersen, J. Dalsgaard, and P. Nornberg (1981), Coastal and near-shore changes correlated with die-back in eel-grass (Zostera marina, L.), Sediment. Geol., 28(3), 163-173, doi:10.1016/ 0037-0738(81)90063-4.

Finnigan, J. (2000), Turbulence in plant canopies, Annu. Rev. Fluid Mech., 32(1), 519-571, doi:10.1146/annurev.fluid.32.1.519.

Folkard, A. M. (2005), Hydrodynamics of model Posidonia oceanica patches in shallow water, Limnol. Oceanogr., 50(5), 1592-1600, doi:10.4319/lo.2005.50.5.1592.
Fonseca, M. S., et al. (1982), Influence of the seagrass, Zostera marina L., on current flow, Estuarine Coastal Shelf Sci., 15, 351-358, doi:10.1016/ 0272-7714(82)90046-4.

Fonseca, M. S., et al. (2002), Modeling seagrass landscape pattern and associated ecological attributes, Ecol. Appl., 12(1), 218-237, doi:10.1890/1051-0761(2002)012[0218:MSLPAA]2.0.CO;2.

Gacia, E., and C. M. Duarte (2001), Sediment retention by a Mediterranean Posidonia oceanica meadow: The balance between deposition and resuspension, Estuarine Coastal Shelf Sci., 52, 505-514, doi:10.1006/ ecss.2000.0753.

Gambi, M. C., et al. (1990), Flume observations on flow dynamics in Zostera marina (eelgrass) beds, Mar. Ecol. Prog. Ser., 61, 159-169, doi:10.3354/meps061159.

García, C. M., M. I. Cantero, Y. Nino, and M. H. Gacia (2005), Turbulence measurements with acoustic Doppler velocimeters, J. Hydraul. Eng., 131(12), 1062-1073, doi:10.1061/(ASCE)0733-9429(2005) 131:12(1062).

Gaylord, B., and M. Denny (1997), Flow and flexibility. I. Effects of size, shape and stiffness in determining wave forces on the stipitate kelps Eisenia arborea and Pterygophora californica, J. Exp. Biol., 200(24), 3141-3164.

Gere, J. M., and S. P. Timoshenko (1999), Mechanics of Materials, Stanley Thornton, Cheltenham, U. K.

Godet, L., et al. (2008), Before and after wasting disease in common eelgrass Zostera marina along the French Atlantic coasts: A general overview and first accurate mapping, Dis. Aquat. Organ., 79(3), 249-255, doi:10.3354/dao01897.

Goldberg, U., and D. Apsley (1997), A wall-distance-free low Re $k-\varepsilon$ turbulence model, Comput. Methods Appl. Mech. Eng., 145(3-4), 227-238, doi:10.1016/S0045-7825(96)01202-9.

Hoerner, S. F. (1965), Fluid-Dynamic Drag, Hoerner Fluid Dyn., Vancouver, B. C., Canada.

Ikeda, S., et al. (2001), Numerical study on turbulent flow and honami in and above flexible plant canopy, Int. J. Heat Fluid Flow, 22, 252-258, doi:10.1016/S0142-727X(01)00087-X.

Järvelä, J. (2002), Flow resistance of flexible and stiff vegetation: A flume study with natural plants, J. Hydrol., 269(1-2), 44-54, doi:10.1016/ S0022-1694(02)00193-2.

Koch, E. W., and S. Beer (1996), Tides, light and the distribution of Zostera marina in Long Island Sound, USA, Aquat. Bot., 53(1-2), 97-107, doi:10.1016/0304-3770(95)01015-7.

Kouwen, N., and T. E. Unny (1970), Flow retardance in vegetated channels, J. Irrig. Drain. Eng., 95, 329-342.

Kouwen, N., and T. E. Unny (1973), Flexible roughness in open channels, J. Hydraul. Div. Am. Soc. Civ. Eng., 99, 713-728.

Kutija, V., and H. T. M. Hong (1996), A numerical model for assessing the additional resistance to flow introduced by flexible vegetation, J. Hydraul. Res., 34(1), 99-114, doi:10.1080/00221689609498766.

Launder, B. E., and D. B. Spalding (1974), The numerical computation of turbulent flows, Comput. Methods Appl. Mech. Eng., 3, 269-289, doi:10.1016/0045-7825(74)90029-2.

López, F., and M. H. García (2001), Mean flow and turbulence structure of open-channel flow through non-emergent vegetation, J. Coastal Eng., $127,392-402$.

Maltese, A., et al. (2007), Laboratory measurements of flow and turbulence in discontinuous distributions of ligulate seagrass, J. Hydraul. Eng., 133(7), 750-760, doi:10.1061/(ASCE)0733-9429(2007)133:7(750).

Morison, J. R., et al. (1950), The force exerted by surface waves on piles, Pet. Trans., 189, 149-154.

Neary, V. S. (2003), Numerical solution of fully developed flow with vegetative resistance, J. Eng. Mech., 129(5), 558-563, doi:10.1061/(ASCE) 0733-9399(2003)129:5(558).

Nepf, H. M. (1999), Drag, turbulence, and diffusion in flow through emergent vegetation, Water Resour. Res., 35(2), 479-489, doi:10.1029/ 1998WR900069.

Nepf, H., and E. Vivoni (2000), Flow structure in depth-limited, vegetated flow, J. Geophys. Res., 105(C12), 28,547-28,557, doi:10.1029/ 2000JC900145.

Nikora, V. I., and D. G. Goring (1998), ADV measurements of turbulence: Can we improve their interpretation?, J. Hydraul. Eng., 124(6), 630-634, doi:10.1061/(ASCE)0733-9429(1998)124:6(630).

Nikora, V. I., and P. M. Rowinski (2008), Rough-bed flows in geophysical, environmental, and engineering systems: Double-averaging approach and its applications-Preface, Acta Geophys., 56(3), 529-533, doi:10.2478/s11600-008-0037-7. 
Olesen, B., et al. (2004), Recolonization dynamics in a mixed seagrass meadow: The role of clonal versus sexual processes, Estuaries, 27(5), 770-780, doi:10.1007/BF02912039.

Peralta, G., et al. (2008), Consequences of shoot density and stiffness for ecosystem engineering by benthic macrophytes in flow dominated areas: A hydrodynamic flume study, Mar. Ecol. Prog. Ser., 368, 103-115, doi:10.3354/meps07574.

Poggi, D., and G. G. Katul (2008), Micro- and macro-dispersive fluxes in canopy flows, Acta Geophys., 56(3), 778-799, doi:10.2478/s11600008-0029-7.

Poggi, D., G. G. Katul, and J. D. Albertson (2004), Momentum transfer and turbulent kinetic energy budgets within a dense model canopy, Boundary Layer Meteorol., 111(3), 589-614, doi:10.1023/B:BOUN. 0000016502.52590.af.

Raupach, M. R. (1992), Drag and drag partition on rough surfaces, Boundary Layer Meteorol., 60(4), 375-395, doi:10.1007/BF00155203.

Sand-Jensen, K. (2008), Drag forces on common plant species in temperate streams: Consequences of morphology, velocity and biomass, Hydrobiologia, 610(1), 307-319, doi:10.1007/s10750-008-9446-5.

Schanz, A., and H. Asmus (2003), Impact of hydrodynamics on development and morphology of intertidal seagrasses in the Wadden Sea, Mar. Ecol. Prog. Ser., 261, 123-134, doi:10.3354/meps261123.

Schutten, J., and A. J. Davy (2000), Predicting the hydraulic forces on submerged macrophytes from current velocity, biomass and morphology, Oecologia, 123, 445-452, doi:10.1007/s004420000348.

Sfriso, A., and A. Marcomini (1997), Macrophyte production in a shallow coastal lagoon. Part I: Coupling with chemico-physical parameters and nutrient concentrations in waters, Mar. Environ. Res., 44(4), 351-375, doi:10.1016/S0141-1136(97)00012-3.

Shimizu, Y., and T. Tsujimoto (1994), Numerical analysis of turbulent open-channel flow over a vegetation layer using a $k$-e turbulence model, J. Hydrosci. Hydraul. Eng., 11(2), 57-67.

Stoesser, T., G. P. Salvador, W. Rodi, and P. Diplas (2009), Large eddy simulation of turbulent flow through submerged vegetation, Transp. Porous Media, 78(3), 347-365, doi:10.1007/s11242-009-9371-8.

Sukhodolov, A., and T. Sukhodolova (2006), Evolution of mixing layers in turbulent flow over submersed vegetation: Field experiments and mea- surement study, in River Flow 2006, edited by A. Ferreira and C. Leal, pp. 525-534, Taylor and Francis, London.

Tamaki, H., et al. (2002), Deterioration of eelgrass, Zostera marina L., meadows by water pollution in Seto Inland Sea, Japan, Mar. Pollut. Bull., 44(11), 1253-1258, doi:10.1016/S0025-326X(02)00218-7.

Temmerman, S., T. J. Bouma, G. Govers, Z. B. Wang, M. B. De Vries, and P. M. J. Herman (2005), Impact of vegetation on flow routing and sedimentation patterns: Three-dimensional modeling for a tidal marsh, J. Geophys. Res., 110, F04019, doi:10.1029/2005JF000301.

Uittenbogaard, R. E. (2003), Modelling turbulence in vegetated aquatic flows, paper presented at Riparian Forest Vegetated Channels Workshop, Cent. of Adv. Stud. of Hydrogeol. Risks in Mt. Areas, Trento, Italy.

Uittenbogaard, R., and G. Klopman (2001), Numerical simulation of wavecurrent driven sediment transport, paper presented at 4th International Conference on Coastal Dynamics, Am. Soc. of Civ. Eng., Lund, Sweden, 11-15 June.

van Katwijk, M. M. (2000), Possibilities for restoration of Zostera marina beds in the Dutch Wadden Sea, Ph.D. thesis, 160 pp, Univ. of Nijmegen, Nijmegen, Netherlands.

Velasco, D., et al. (2008), A new integrated, hydro-mechanical model applied to flexible vegetation in riverbeds, J. Hydraul. Res., 46(5), 579-597, doi:10.3826/jhr.2008.2986.

Vogel, S. (1981), Life in Moving Fluids, 352 pp., Willard Grant, Boston, Mass.

Wilson, C. A. M. E., T. Stoesser, R. D. Bates, and A. Batemann Pinzen (2003), Open channel flow through different forms of submerged flexible vegetation, J. Hydraul. Eng., 129(11), 847-853, doi:10.1061/(ASCE) 0733-9429(2003)129:11(847).

Worcester, S. E. (1995), Effects of eelgrass beds on advection and turbulent mixing in low current and low shoot density environments, Mar. Ecol. Prog. Ser., 126, 223-232, doi:10.3354/meps126223.

J. T. Dijkstra, Department of Hydraulic Engineering, Faculty of Civil Engineering and Geosciences, Delft University of Technology, Stevinweg 1, NL-2628 CN Delft, Netherlands. (j.t.dijkstra@tudelft.nl)

R. E. Uittenbogaard, Deltares, Rotterdamseweg 185, NL-2629 HD Delft, Netherlands. (rob.uittenbogaard@deltares.nl) 